\title{
Desenvolvimento local em territórios empobrecidos: possibilidades de inclusão social e produtiva de produtores rurais
}

\author{
Local development in impoverished regions: possibilities of socioeconomic \\ inclusion for farmers
}

\section{Le développement local dans les territoires pauvres: chances de l'inclusion sociale et productive des agriculteurs}

El desarrollo local en los territorios empobrecidos: posibilidades de inclusión social y productiva de los campesinos

\author{
Gabriel Medina* \\ Evandro Novaes* \\ Sônia Milagres Teixeira*
}

Recebido em 21/07/2016; revisado e aprovado em 06/10/2016; aceito em 31/10/2016

DOI: http:/ / dx.doi.org/10.20435/1984-042X-2017-v.18-n.1(03)

\begin{abstract}
Resumo: No artigo são exploradas as possibilidades de desenvolvimento dos territórios rurais brasileiros mais pobres. São analisadas as condições de vida dos agricultores locais entrevistados em 7.975 domicílios rurais de 37 territórios de todo o país. Enquanto cerca de $80 \%$ dos agricultores revelam ter ativos disponíveis para a produção agropecuária, apenas $20 \%$ têm boas condições de comercialização e acesso às políticas agrícolas.

Palavras-chave: agricultura familiar; pobreza rural; políticas agrícolas.

Abstract: This study explores the possibilities for development in poor Brazilian rural territories. It assesses the livelihoods of local farmers interviewed in 7,975 households in 37 different territories across the country. While $80 \%$ of farmers have potential for production in their farms, only $20 \%$ have good access to markets and agricultural policies.

Key words: family farming; rural poverty; agricultural policy.

Résumé: Cette étude explore les possibilités de développement dans les territoires ruraux brésiliens pauvres. Il est basé sur les moyens d'existence des agriculteurs locaux interrogés dans 7.975 ménages dans 37 territoires différents à travers le pays. Alors que $80 \%$ des agriculteurs ont un certain potentiel de production, seulement $20 \%$ ont un bon accès aux marchés et les politiques agricoles.

Mots-clés: l'agriculture familiale; la pauvreté rurale; la politique agricole.

Resumen: Este estudio explora las posibilidades de desarrollo local en los territorios rurales brasileños pobres. Se basa en la evaluación de los medios de vida de los campesinos entrevistados en 7.975 hogares en 37 territorios en todo el país. Mientras que el $80 \%$ de los agricultores tienen algún potencial de producción, sólo el 20\% tienen un buen acceso a los mercados y las políticas agrícolas. Palabras clave: agricultura familiar; la pobreza rural; la política agrícola.
\end{abstract}

\section{INTRODUÇÃO}

A economia brasileira vem crescendo ao longo dos últimos anos, e o país é classificado como a sétima maior economia do mundo pelo Fundo Monetário Internacional (FMI). Segundo o Instituto Brasileiro de Geografia e Estatística (IBGE, 2016) o Produto Interno Bruto (PIB) per capta cresceu de $\mathrm{R} \$ 4,4$ mil, em 1995, para
R\$ 28,8 mil, em 2015. Parte importante do desenvolvimento brasileiro vem do campo, com o agronegócio representando 23\% PIB nacional (CEPEA, 2014). Em 2006, o Valor Bruto da Produção (VBP) rural brasileira foi composto por $\mathrm{R} \$ 84$ bilhões da agricultura patronal e por R\$ 57 bilhões da agricultura familiar (FRANÇA; DEL GROSSI; MARQUES, 2009).

\footnotetext{
* Universidade Federal de Goiás, Goiânia, Goiás, Brasil.
} 
Além do avanço da economia nacional, foi crescente a inclusão social no país com melhorias nas condições de vida dos brasileiros. Nos últimos dez anos, 35 milhões de pessoas passaram para a classe média, que passou a abrigar metade dos brasileiros que viviam no campo, no início dos anos 2000 (NERI; MELO; MONTE, 2012). Pertencem à classe média famílias com renda per capita de $\mathrm{R} \$ 291,00$ a $\mathrm{R} \$ 1.019,00$ mensais. O crescimento da classe média rural foi apoiado pela crescente importância das transferências públicas na composição da renda da população rural que representou $11,7 \%$ da renda total em 2009 , com crescimento de 21,4\% em relação a 2003 (NERI; MELO; MONTE, 2012).

Apesar desses avanços, segundo a Organização das Nações Unidas (ONU), o Brasil é o oitavo país mais desigual do mundo, com índice Gini de 0,515 no ano de 2014, embora se tenha observado melhora nos últimos anos (HOFFMANN; NEY, 2008; IPEA, 2015). No ano de 2010, o Índice de Gini no meio rural brasileiro era de 0,727 , ao passo que o mesmo dado geral para o país era de 0,533 (IPEA, 2015). Segundo dados do Censo realizado pelo IBGE, em 2010 o país contava 16,27 milhões de pessoas em situação de extrema pobreza, representando $8,5 \%$ da população (IBGE, 2010). Segundo o IBGE (2010), $46,7 \%$ das pessoas na linha de extrema pobreza em 2010 residiam em área rural, apesar de que apenas $15,6 \%$ da população brasileira moravam no campo. Um em cada quatro brasileiros que viviam no campo se encontrava em extrema pobreza. Do total de estabelecimentos rurais brasileiros, aproximadamente $8,19 \%$ tinham renda mensal superior a 10 salários mínimos, 18,86\% entre dois e 10 salários mínimos, e 72,95\% inferior a dois salários mínimos, e enfrentavam dificuldades para melhorar de vida pela agricultura (ALVES; ROCHA, 2010). A pobreza rural tem se mostrado mais difícil de ser superada do que a pobreza urbana tanto por causa da estrutura fundiária concentrada, quanto pela elevada participação do emprego precário na agricultura (NEY; SOUZA; PONCIANO, 2011).

A agricultura familiar representa o segundo maior grupo em extrema pobreza no Brasil rural, com 756 mil famílias (3,4 milhões de pessoas) extremamente pobres (o primeiro grupo é formado por famílias sem inserção produtiva) (DEL GROSSI, 2012). O Brasil conta com 164 territórios rurais e 120 territórios da cidadania, que são áreas de depressão socioeconômica reconhecida (MDA, 2008). Esses territórios são caracterizados por baixo IDH, maior concentração de beneficiários do Programa Bolsa Família, concentração de agricultura familiar e assentamentos da reforma agrária, concentração de populações quilombolas e indígenas e por estar em municípios com baixo dinamismo econômico (MDA, 2008). Mesmo sendo áreas do Brasil rural com baixo IDH, os territórios são regiões de articulação das políticas públicas (LEITE; WESZ JÚNIOR, 2012), com identidade própria (ECHEVERRI, 2009) e têm potencial de desenvolvimento a partir da valorização dos atores e produtos locais (VAN DER PLOEG et al., 2000).

Por essas razões, o desenvolvimento local nos territórios é um tema cada vez mais emergente frente aos processos de transformações do espaço mundial (FERREIRA, 2014). Não obstante, estudos revelam a prevalência de políticas orientadas para a assistência social e o arrefecimento das ações públicas que buscam alterações mais estruturais em favor das famílias rurais pobres (ZIMMERMANN et al., 2014; DELGADO; GRISA, 2014). Ações de inclusão produtiva são estratégicas, considerando a relevância da renda do trabalho, que representa $52,1 \%$ da renda total dos domicílios rurais brasileiros e apresentou crescimento de $4,5 \%$ no período de 2003 a 2009 (NERI; MELO; MONTE, 2012). Estudos sugerem que maior acesso a mercados e a políticas agrícolas tem 
grande potencial de contribuir para o desenvolvimento local nos territórios rurais (MEDINA; NOVAES, 2014).

Para Martins (1999), a inclusão não passa apenas pela promoção do acesso aos ativos ou a recursos materiais e financeiros, mas também de processos radicais de democratização, que libertem os indivíduos da tutela e controle exercido pelas elites e pelos mediadores. Estudos internacionais refletem a relevância das liberdades individuais como pilar central do desenvolvimento (SEN, 1999). Nesse sentido, a valorização dos agricultores, em particular os agricultores familiares, como dinamizadores das economias locais, é considerado eixo fundamental de ação (VEIGA, 2001; SACHS, 2001; ABRAMOVAY, 1992).

Uma perspectiva fundamental para pensar as possibilidades de inclusão social e produtiva é a percepção dos próprios agricultores sobre suas condições de vida. Adicional aos dados objetivos do Censo, analisados em diferentes oportunidades (GUILHOTO et al., 2007; FRANÇA; DEL GROSSI; MARQUES, 2009; ALVES; ROCHA, 2010; NERI; MELO; MONTE, 2012), a percepção dos agricultores revela a perspectiva local para aspectos fundamentais do desenvolvimento.

Este estudo busca explorar as possibilidades de desenvolvimento local em territórios rurais empobrecidos no Brasil a partir de dados objetivos e da perspectiva dos agricultores locais. Especificamente objetiva-se: a) Caracterizar as condições de vida nos domicílios rurais brasileiros (familiares e não familiares) em áreas com menor dinamismo econômico; b) Identificar os ativos potenciais para o desenvolvimento local existentes nos domicílios rurais; e c) Contrastar a situação nas diferentes regiões do país e verificar sua dependência de intervenção das políticas públicas em apoio ao desenvolvimento local.

\section{METODOLOGIA}

O estudo revela as condições de vida dos agricultores de domicílios rurais em amostra de territórios com menor dinamismo econômico a partir de dados coletados em 16 estados das diferentes regiões brasileiras. A pesquisa envolveu 37 territórios rurais em todo o Brasil com uma amostra por território, atendendo ao critério de erro máximo de $5 \%$ em um esquema de amostragem probabilística (WALTER, 2011). A pesquisa de campo foi realizada entre agosto de 2010 e junho de 2012 em uma parceria entre 27 universidades brasileiras apoiadas pelo Ministério do Desenvolvimento Agrário (MDA) e pelo Conselho Nacional de Desenvolvimento Científico e Tecnológico (CNPq).

Foram realizadas entrevistas em 10.362 domicílios sendo que 7.975 tinham alguma produção agropecuária e foram considerados na análise. Desses, 4.342 foram domicílios de agricultores familiares, e os demais, de agricultores não familiares. Os agricultores familiares foram identificados de acordo com a definição legal (Lei $\mathrm{n}^{\mathrm{o}} 11.326$ de 2006): possuir menos de quatro módulos fiscais, empregar trabalho principalmente da família, ter renda proveniente principalmente da produção na propriedade, ser um estabelecimento administrado pela família e possuir no máximo dois empregados permanentes (BRASIL, 2006).

Além da diferenciação dos indicadores e percepção entre agricultores familiares e não familiares por região geográfica, os domicílios da amostra são estratificados a partir de dois critérios: 1. A percepção do responsável pelo domicílio sobre sua situação de renda e 2 . O acesso à infraestrutura básica como energia elétrica, água encanada e esgoto, bem como o número de utensílios domésticos como fogão a gás, geladeira e telefone. As famílias foram separadas em duas classes: aquelas com menos de quatro 
ou mais de quatro utensílios (incluindo a infraestrutura). Dessa maneira, a seguinte estratificação foi constituída:

- Estrato 1 - Mais pobre - considera-se sua situação de renda de ruim a péssima e conta com até quatro utensílios na residência. Esses casos somam 1.023 domicílios e representam os domicílios considerados mais pobres da amostra;

- Estrato 2 - Intermediário - considera-se sua situação de renda regular. Esses casos somam 5.473 domicílios e foram considerados em situação intermediária;

- Estrato 3 - Menos pobre - considera-se sua situação de renda de boa a ótima e conta com mais de quatro utensílios na residência. Esses casos somam 1.479 domicílios e foram considerados os domicílios menos pobres da amostra.

As comparações entre valores médios foram realizadas através do teste de Tukey com um nível de significância ( $\alpha$ ) de 5\%. Essas análises foram realizadas com o intuito de comparar as cinco regiões do país (N, NE, S, SE e CO) e as três classes de pobreza. Para os dados de porcentagem, foram estimadas margens de erros associados às estimativas feitas com base na amostra. Essa margem de erro foi calculada considerando um intervalo de significância de 95\%, conforme a equação a seguir:

$$
e=1,96 \sqrt{\frac{p \times(1-p)}{n}}, \text { em que } p \text { é por- }
$$

centagem estimada para o parâmetro em questão e $n$ é o tamanho amostral, que é igual a 1.023 no caso dos mais pobres, 5.473 para as famílias de nível intermediário e 1.479 no caso dos menos pobres.

\section{RESULTADOS}

\subsection{Situação atual dos domicílios rurais}

Os domicílios amostrados são essencialmente pobres. A renda foi considerada regular em 46,4\% dos domicílios e ruim ou péssima em $26,8 \%$. Em relação aos utensílios domésticos básicos, ainda existem $5,9 \%$ das famílias rurais sem energia elétrica, 12,2\% sem água dentro ou próximo da casa, $26,7 \%$ sem banheiro dentro da casa, $7,3 \%$ sem fogão a gás, $14,7 \%$ sem geladeira e 39,7\% sem telefone. Computador ainda é um recurso muito distante dos agricultores entrevistados, já que somente $6,1 \%$ das famílias entrevistadas possuem esse recurso.

Uma análise das proporções dos níveis de pobreza entre as regiões do país, como descrito por Pochmann e Amorin (2003), confirma-se nesse estudo com as regiões Norte e Nordeste de fato sendo as menos favorecidas. Essas regiões possuem somente $8,6 \%$ e $18,4 \%$ das famílias classificadas no nível menos pobre, respectivamente. Já nas outras regiões, o estrato menos pobre compreende de 20,1\% (Sudeste) a 31,4\% (Centro-Oeste) das famílias.

Referente à transferência de renda governamental, 48,7\% dos domicílios têm a renda complementada com o programa Bolsa Família. Entre os mais pobres, o benefício está presente em $65,8 \%$ dos domicílios enquanto que os menos pobres contam 33,8\% dos domicílios com ajuda do Bolsa Família (Tabela 1). Existem diferenças significativas entre as regiões, com maior presença dos programas de transferência de renda entre o estrato mais pobre no Norte e Nordeste (Figura 1). 


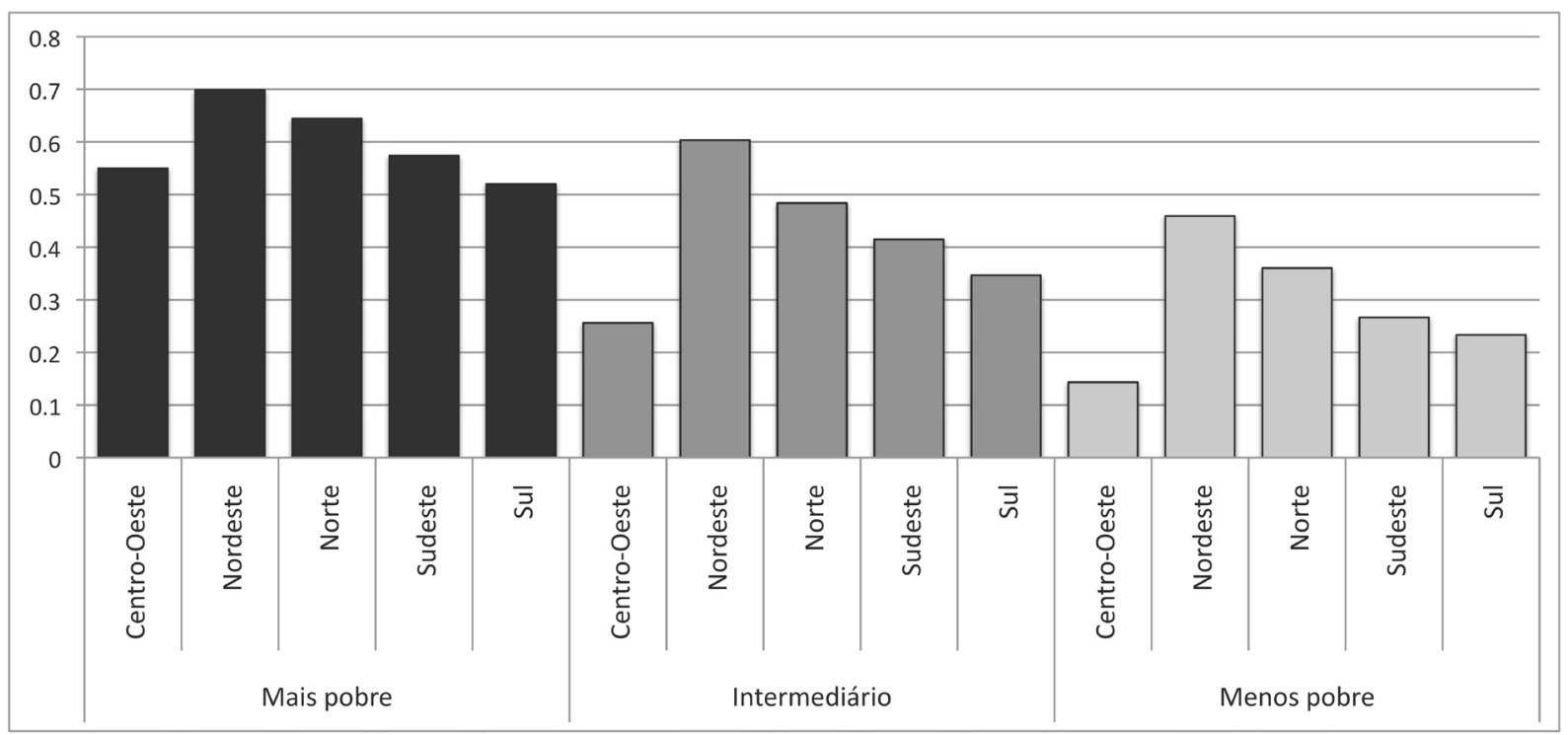

Figura 1 - Porcentagem de famílias que recebem assistência de programas de transferência de renda do governo entre as diferentes regiões do país e entre os diferentes níveis de pobreza

Além do programa Bolsa Família, outra fonte de renda importante é a aposentadoria, presente em $37,6 \%$ dos domicílios. Entre os mais pobres, a aposentadoria está presente em $22,7 \%$ dos domicílios enquanto que, entre os menos pobres, está presente em $50,1 \%$. A maior incidência de aposentados nas famílias dos domicílios com melhor renda sugere a dependência dessa fonte de renda para as famílias e as limitações das demais fontes (Tabela 1).

A porcentagem de adultos alfabetizados e com o ensino fundamental concluído é de $64,2 \%$ e de $17 \%$ respectivamente. Entre os mais pobres, o acesso à alfabetização e ao ensino fundamental é ainda menor (Tabela 1). Considerando a importância da educação para as novas gerações, um dado alarmante dessa pesquisa é que $9,7 \%$ das famílias com crianças e adolescentes em idade escolar não possuem todos seus membros matriculados e frequentando a escola. A situação é ainda mais grave entre os mais pobres em que $12,2 \%$ das famílias possuem crianças e adolescentes não matriculados e/ou não frequentando a escola. Segundo Neri, Melo e Monte (2012) as pessoas das classes $^{1}$ A e B do campo brasileiro têm, em média, sete anos de estudos, enquanto as classes C, D e E têm respectivamente 4,2; 3,5 e 3 anos.

\footnotetext{
${ }^{1}$ Renda domiciliar por classe em Reais: E (0 a 705), D (705 a 1126), C (705 a 4854), B (4854 a 6329) e A (6328 a mais)
} 
Tabela 1 - Acesso a políticas públicas básicas pelos diferentes estratos da população nos territórios rurais empobrecidos (em porcentagem da amostra selecionada)

\begin{tabular}{|c|c|c|c|c|c|}
\hline & \multirow[b]{2}{*}{$\begin{array}{l}\text { Recebe trans- } \\
\text { ferência de } \\
\text { renda do Bol- } \\
\text { sa Família }^{1}\end{array}$} & \multirow[b]{2}{*}{$\begin{array}{l}\text { Recebe } \\
\text { aposenta- } \\
\text { doria }^{1}\end{array}$} & \multicolumn{3}{|c|}{ Educação } \\
\hline & & & $\begin{array}{l}\text { Alfabetização } \\
\text { de todos os } \\
\text { membros da } \\
\text { família maio- } \\
\text { res de } 15 \text { anos }^{1}\end{array}$ & $\begin{array}{l}\text { Conclusão } \\
\text { do ensino } \\
\text { fundamental } \\
\text { por todos os } \\
\text { adultos }^{1}\end{array}$ & $\begin{array}{l}\text { Matrícula e fre- } \\
\text { quência escolar } \\
\text { de todas as } \\
\text { crianças e ado- } \\
\text { lescentes em } \\
\text { idade escolar }\end{array}$ \\
\hline Mais pobre & $65.8 \pm 1.04$ & $22.7 \pm 0.92$ & $49.5 \pm 1.10$ & $9.2 \pm 0.63$ & $87.8 \pm 0.72$ \\
\hline Intermediário & $49.5 \pm 1.10$ & $36.9 \pm 1.06$ & $65.7 \pm 1.04$ & $17.1 \pm 0.83$ & $90.5 \pm 0.64$ \\
\hline Menos pobre & $33.8 \pm 1.04$ & $50.1 \pm 1.10$ & $68.9 \pm 1.02$ & $22.1 \pm 0.91$ & $91.9 \pm 0.60$ \\
\hline
\end{tabular}

Fonte: dados da pesquisa. ${ }^{1} \mathrm{~A}$ frente dos percentuais estão margens de erro estimados com um intervalo de confiança de $95 \%$.

Dos domicílios em que foram realizadas entrevistas, $54,3 \%$ são de agricultores familiares. Dentre os mais pobres, $62,5 \%$ são agricultores familiares e, entre os menos pobres, $47,8 \%$ são agricultores familiares. Essa predominância de agricultores familiares entre os pobres é percebida em todos os critérios de es- tratificação dos agricultores familiares e também em todas as regiões geográficas, com exceção do Centro-Oeste e do Sudeste (Tabela 2). Não obstante, mesmo entre os agricultores familiares, existe um contingente de $46 \%$ que não recebem qualquer assistência do governo tipo Bolsa Família. 
possibilidades de inclusão social e produtiva de produtores rurais

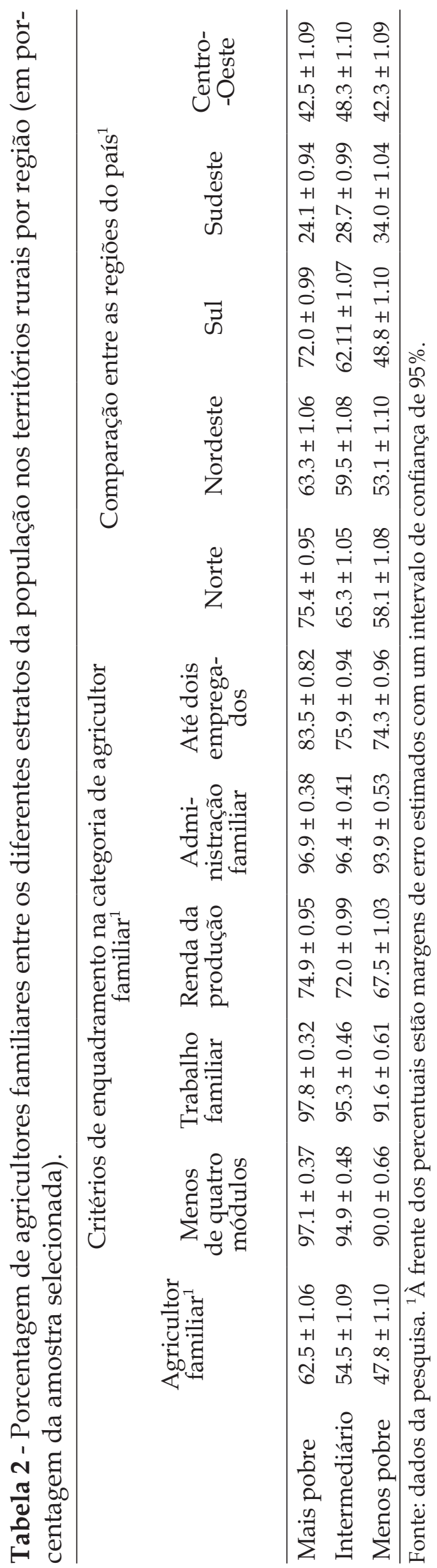




\subsection{Ativos potenciais para o desenvolvimento rural}

A terra e a mão de obra são os principais ativos que, se produtivos e bem remunerados, podem ajudar a retirar as famílias rurais da pobreza. Em relação à terra, os domicílios com áreas maiores, com maior produtividade e melhor conservação dos recursos naturais estão em melhores condições financeiras. Dentre os mais pobres, apenas 2,9\% dos estabelecimentos têm acima de quatro módulos enquanto que, entre os menos pobres, $10 \%$ têm mais que quatro módulos fiscais (Tabela 3).

Adicionalmente, a produtividade da terra é considerada ótima ou boa por
41,3\% dos domicílios, regular para 39,2\% e ruim ou péssima para 19,3\%. Entre os domicílios em melhor condição, $62 \%$ avaliam de forma positiva a produtividade da terra, enquanto apenas 29,8\% entre aqueles em pior condição percebem da mesma maneira. As famílias com melhor classificação entre os níveis de pobreza também têm visão mais otimista sobre a conservação dos recursos naturais (água, solo e vegetação) (Tabela 3). Consideram boas ou ótimas as condições de conservação de seus recursos naturais, a seguinte porcentagem do total de domicílios entrevistados: $60,2 \%$ a conservação das fontes de água, 53,1\% a conservação do solo e $53,8 \%$ a conservação da vegetação nativa.

Tabela 3 - Condições da área (terra) entre os diferentes estratos da população nos territórios rurais (em porcentagem da amostra selecionada)

\begin{tabular}{lrrrrr}
\hline & $\begin{array}{c}\text { Área acima de } \\
\text { quatro módulos } \\
\text { fiscais }\end{array}$ & $\begin{array}{c}\text { Produtividade } \\
\text { da terra }\end{array}$ & $\begin{array}{c}\text { Conservação } \\
\text { de água }^{1}\end{array}$ & $\begin{array}{c}\text { Conservação } \\
\text { do solo }^{1}\end{array}$ & $\begin{array}{c}\text { Preservação } \\
\text { da vegetação } \\
\text { nativa }^{1}\end{array}$ \\
\hline Mais pobre & $2.9 \pm 0.37$ & $29.8 \pm 1.01$ & $50.7 \pm 1.10$ & $42.1 \pm 1.09$ & $47.0 \pm 1.10$ \\
Intermediário & $5.1 \pm 0.49$ & $37.9 \pm 1.07$ & $58.5 \pm 1.08$ & $50.5 \pm 1.10$ & $52.7 \pm 1.10$ \\
Menos pobre & 10.00 .66 & $62.0 \pm 1.07$ & $73.0 \pm 1.00$ & $70.7 \pm 1.00$ & $62.5 \pm 1.07$ \\
\hline
\end{tabular}

Fonte: dados da pesquisa. À frente dos percentuais estão margens de erro estimadas com intervalo de confiança de $95 \%$. ${ }^{1}$ Dados referentes à proporção de agricultores que consideram suas propriedades como ótimas ou boas em relação aos aspectos avaliados.

Em relação à força de trabalho, estão em melhor condição os domicílios que possuem famílias significativamente menores, mas com maior porcentagem de pessoas com trabalho não agrícola para terceiros. Entre os mais pobres, o tamanho médio das famílias é de 4,9 membros. Já entre os menos pobres, as famílias possuem em média 3,9 membros, sendo essa diferença significativa (Tabela 4). Além disso, as famílias mais pobres possuem maior proporção de membros inativos, seja dentro ou fora da propriedade, e a mão de obra é percebida de forma menos produtiva por essas famílias (Tabela 4). Em média, a produtividade do trabalho é considerada boa ou ótima por 31,5\% dos domicílios, regular por $43,4 \%$ e ruim ou péssima por $25,1 \%$. Porém, entre os mais pobres, a produtividade do trabalho é considerada boa ou ótima por somente $15,9 \%$ dos domicílios, regular por 34,6\% e ruim ou péssima por $59,5 \%$.

As famílias do Norte e Nordeste são significativamente mais numerosas (Tabela 5). Nessas regiões, as famílias também possuem baixa proporção de pessoas ativas, seja dentro ou fora do domicílio (Tabela 5). A produção agropecuária como fonte de renda está presente em $80,8 \%$ dos domicílios, o trabalho agrícola para terceiros em $28,5 \%$, e o trabalho 
não agrícola para terceiros em $17,7 \%$ dos domicílios, números altos que refletem a busca de alternativas de renda fora do domicílio. Entre os mais pobres, estão aqueles que investem sua mão de obra na atividade agropecuária e no trabalho agrícola para terceiros e, entre os menos pobres, aqueles com maior porcentagem de trabalho não agrícola para terceiros (Tabela 6). Em relação à produtividade da mão de obra, as famílias com melhor nível de renda apresentam percepção mais positiva em relação aos resultados da produção levando-se em conta a quantidade de trabalho utilizada.

Tabela 4 - Tamanho médio das famílias, média da porcentagem de membros que trabalham dentro e fora das propriedades, e porcentagem de famílias com percepção positiva sobre a produtividade do trabalho entre os diferentes níveis de pobreza.

\begin{tabular}{lrrrr}
\hline & $\begin{array}{l}\text { Tamanho } \\
\text { médio das } \\
\text { famílias }^{1}\end{array}$ & $\begin{array}{l}\text { Média de membros } \\
\text { trabalhando dentro } \\
\text { da propriedade }{ }^{1}(\%)\end{array}$ & $\begin{array}{l}\text { Média de membros } \\
\text { trabalhando fora da } \\
\text { propriedade }(\%)\end{array}$ & $\begin{array}{l}\text { Produtividade } \\
\text { do trabalho } \\
\text { ótima ou boa }{ }^{2}\end{array}$ \\
\hline Mais pobre & $4.9 \mathrm{a}$ & $51.5 \mathrm{~b}$ & $3.3 \mathrm{c}$ & $15.9 \pm 0.80$ \\
Intermediário & $4.2 \mathrm{~b}$ & $55.0 \mathrm{a}$ & $5.3 \mathrm{~b}$ & $27.1 \pm 0.98$ \\
Menos pobre & $3.9 \mathrm{C}$ & $55.7 \mathrm{a}$ & $6.8 \mathrm{a}$ & $59.0 \pm 1.08$ \\
\hline
\end{tabular}

Fonte: dados da pesquisa. ${ }^{1}$ As letras a frente das estimativas indicam os resultados do teste de Tukey. ${ }^{2} \mathrm{~A}$ frente dos percentuais estão margens de erro estimados com um intervalo de confiança de $95 \%$.

Tabela 5 - Tamanho médio das famílias entre as diferentes regiões do país e porcentagem de membros das famílias que trabalham dentro e fora da propriedade.

\begin{tabular}{lrrr}
\hline & $\begin{array}{c}\text { Tamanho médio } \\
\text { das famílias }^{1}\end{array}$ & $\begin{array}{c}\text { Média de membros } \\
\text { trabalhando dentro da } \\
\text { propriedade }^{1}(\%)\end{array}$ & $\begin{array}{c}\text { Média de membros } \\
\text { trabalhando fora da } \\
\left.\text { propriedade }^{1} \%\right)\end{array}$ \\
\hline Norte & $4.9 \mathrm{a}$ & $55.4 \mathrm{~b}$ & $2.8 \mathrm{c}$ \\
Nordeste & $4.3 \mathrm{~b}$ & $51.8 \mathrm{c}$ & $5.4 \mathrm{~b}$ \\
Sudeste & $3.9 \mathrm{C}$ & $59.5 \mathrm{a}$ & $7.6 \mathrm{a}$ \\
Sul & $3.8 \mathrm{~cd}$ & $58.4 \mathrm{ab}$ & $7.6 \mathrm{a}$ \\
Centro-Oeste & $1.6 \mathrm{~d}$ & $1.5 \mathrm{ab}$ & $5.1 \mathrm{~b}$ \\
\hline
\end{tabular}

Fonte: dados da pesquisa. ${ }^{1}$ As letras à frente das estimativas indicam os resultados do teste de Tukey.

Em relação à diversificação de atividades, as famílias menos pobres possuem significativamente menos fontes de renda. Os mais pobres são os que mais dependem da produção agropecuária, do trabalho agrícola para terceiros e do processamento de produtos (Tabela 6). Os menos pobres têm maior dependência da aposentadoria (Tabela 1), do trabalho não agrícola e do arrendamento de terras (Tabela 6). 
Tabela 6 - Diversidade e contribuição de algumas das principais fontes de renda entre as diferentes classes de pobreza (em porcentagem da amostra selecionada).

\begin{tabular}{|c|c|c|c|c|c|c|}
\hline & \multirow[b]{2}{*}{$\begin{array}{l}\text { Número } \\
\text { médio de } \\
\text { fontes de } \\
\text { renda dife- } \\
\text { rentes }^{1}\end{array}$} & \multicolumn{5}{|c|}{ Contribuição de diversas fontes de renda (\%) } \\
\hline & & $\begin{array}{l}\text { Produção } \\
\text { agrícola / } \\
\text { pecuária / } \\
\text { pesqueira / } \\
\text { extrativista }{ }^{2}\end{array}$ & $\begin{array}{l}\text { Trabalho } \\
\text { agrícola para } \\
\text { terceiros }\end{array}$ & $\begin{array}{l}\text { Trabalho } \\
\text { não agrícola } \\
\text { (serviços, } \\
\text { comércio ou } \\
\text { indústria) }\end{array}$ & $\begin{array}{l}\text { Processa- } \\
\text { mento de } \\
\text { produtos }\end{array}$ & $\begin{array}{l}\text { Arrenda- } \\
\text { mento de } \\
\text { área }^{2}\end{array}$ \\
\hline Mais pobre & $2.6 \mathrm{a}$ & $81.1 \pm 0.86$ & $36.7 \pm 1.06$ & $11.9 \pm 0.71$ & $17.1 \pm 0.83$ & $2.3 \pm 0.33$ \\
\hline Intermediário & $2.5 \mathrm{a}$ & $81.4 \pm 0.85$ & $28.3 \pm 0.98$ & 18.10 .85 & $12.2 \pm 0.72$ & 3.40 .40 \\
\hline Menos pobre & $2.4 \mathrm{~b}$ & $78.2 \pm 0.91$ & $23.6 \pm 0.93$ & $20.0 \pm 0.88$ & 8.70 .62 & $4.2 \pm 0.44$ \\
\hline
\end{tabular}

Fonte: dados da pesquisa. ${ }^{1}$ As letras a frente das estimativas indicam os resultados do teste de Tukey.

${ }^{2} \grave{A}$ frente dos percentuais estão margens de erro estimados com um intervalo de confiança de $95 \%$.

\subsection{Potencial de intervenção das políticas públicas}

Melhorias na produtividade da terra e na remuneração do trabalho podem ser favorecidas por fatores exógenos ao domicílio rural, como mercado, sociedade e políticas públicas. Na amostra, os agricultores com melhor acesso a esses fatores estão em melhor situação.

Referente aos mercados, estão melhores os domicílios que vendem via cooperativas ou associações, ou que dispõem de intermediadores para a comercialização (Tabela 7). Não obstante, o acesso a mercados via cooperativas ou associações é limitado, pois 76,3\% dos domicílios rurais nunca vendem, 12,6\% vendem às vezes e apenas $11,3 \%$ sempre vendem via cooperativas e associações. As regiões cujas famílias apresentaram melhor desempenho na comercialização via associações e cooperativas foram as Centro-Oeste, Sudeste e Sul (Tabela 8).

Já a atuação de atravessadores é avaliada como ruim por $60,0 \%$ dos domicílios e como boa por $38,9 \%$ dos domicílios.
Porém há diferenças entre as classes de pobreza, sendo que a maioria dos menos pobres avalia a atuação dos atravessadores de maneira positiva. Também estão melhores aqueles que participam de organizações comunitárias, da política e da vida cultural local. Do total, 53,5\% das famílias percebem de forma positiva sua participação em organizações comunitárias; 45,8\% em relação à participação em atividades políticas no município ou região e 39,5\% em atividades culturais.

Em relação às políticas públicas para a produção, as famílias que percebem como mais fácil o acesso aos programas do governo e às políticas de crédito e assistência estão em melhor condição (Tabela 7). Não obstante, das famílias entrevistadas, apenas $24,8 \%$ consideram fácil o acesso aos programas do governo, $20,7 \%$ consideram fácil o acesso ao crédito rural, e 19,8\% consideram fácil o acesso à assistência técnica. No contraste entre as regiões, o Norte aparece como aquela com maiores dificuldades de acesso às políticas e o Centro-Oeste e Sul como as regiões com acesso relativamente melhor (Tabela 8). 
Tabela 7 - Condições de acesso ao mercado, de convívio social e de acesso às políticas públicas entre os diferentes estratos da população nos territórios rurais (em porcentagem da amostra selecionada)

\begin{tabular}{|c|c|c|c|c|c|c|c|c|}
\hline & \multicolumn{2}{|c|}{ Comercialização $^{1}$} & \multicolumn{3}{|c|}{ Participação ótima ou boa ${ }^{1}$} & \multicolumn{3}{|c|}{$\begin{array}{l}\text { Facilidade de acesso às polí- } \\
\quad \text { ticas públicas }{ }^{1}\end{array}$} \\
\hline & $\begin{array}{l}\text { Vende via } \\
\text { cooperati- } \\
\text { vas ou as- } \\
\text { sociações }\end{array}$ & $\begin{array}{c}\text { Avalia os } \\
\text { interme- } \\
- \\
\text { diários } \\
\text { positiva- } \\
\text { mente }\end{array}$ & $\begin{array}{c}\text { Em orga- } \\
\text { nizações } \\
\text { comunitá- } \\
\text { rias }\end{array}$ & $\begin{array}{l}\text { Na polí- } \\
\text { tica }\end{array}$ & $\begin{array}{l}\text { Em ati- } \\
\text { vidades } \\
\text { culturais }\end{array}$ & $\begin{array}{l}\text { Progra- } \\
\text { mas de } \\
\text { governo }\end{array}$ & Crédito & $\begin{array}{l}\text { Assis- } \\
\text { tência } \\
\text { técnica }\end{array}$ \\
\hline ais & $11.9 \pm 0.71$ & $29.4 \pm 1.00$ & $43.01 \pm 1.08$ & 42.0 & 06 & 20. & .71 & .71 \\
\hline & & & & & & & & \\
\hline & 29.5 & 50.6 & & & 45. & 33.0 & & \\
\hline \multicolumn{9}{|c|}{$\begin{array}{l}\text { Fonte: dados da pesquisa. }{ }^{1} \mathrm{~A} \text { frente dos percentuais estão margens de erro estimados com um } \\
\text { intervalo de confiança de } 95 \% \text {. }\end{array}$} \\
\hline \multicolumn{9}{|c|}{$\begin{array}{l}\text { Tabela } 8 \text { - Condições de acesso ao mercado, de convívio social e de acesso às políticas } \\
\text { públicas entre as diferentes regiões do país (em porcentagem da amostra selecionada) }\end{array}$} \\
\hline & \multicolumn{2}{|c|}{ Comercialização $^{1}$} & \multicolumn{3}{|c|}{ Participação ótima ou boa ${ }^{1}$} & \multicolumn{3}{|c|}{$\begin{array}{l}\text { Facilidade de acesso às polí- } \\
\text { ticas públicas }{ }^{1}\end{array}$} \\
\hline & $\begin{array}{l}\text { Vende a } \\
\text { produção } \\
\text { via coope- } \\
\text { rativas ou } \\
\text { associações }\end{array}$ & $\begin{array}{l}\text { Avalia os } \\
\text { intermediá- } \\
\text { rios positi- } \\
\text { vamente }\end{array}$ & $\begin{array}{c}\text { Em orga- } \\
\text { nizações } \\
\text { comunitá- } \\
\text { rias }\end{array}$ & $\begin{array}{l}\text { Na polí- } \\
\text { tica }\end{array}$ & $\begin{array}{l}\text { Em ati- } \\
\text { vidades } \\
\text { culturais }\end{array}$ & $\begin{array}{l}\text { Progra- } \\
\text { mas de } \\
\text { governo }\end{array}$ & Crédito & $\begin{array}{l}\text { Assistên- } \\
\text { cia téc- } \\
\text { nica }\end{array}$ \\
\hline & & & & & & & & \\
\hline & & & & & & & & 0.83 \\
\hline deste & $39.8 \pm 1.08$ & $38.5 \pm 1.07$ & 56 & $44.4 \pm$ & $34.3 \pm$ & $22.0 \pm 0.91$ & $19.4 \pm 0.87$ & $22.3 \pm 0.92$ \\
\hline & & & & & & & & \\
\hline Centro-Oeste & $44.3 \pm 1.09$ & $47.4 \pm 1.10$ & $51.1 \pm 1.10$ & $39.4 \pm 1.07$ & $34.4 \pm 1.04$ & $21.3 \pm 0.90$ & $20.9 \pm 0.89$ & $32.5 \pm 1.03$ \\
\hline
\end{tabular}

Fonte: dados da pesquisa. ${ }^{1}$ À frente dos percentuais estão margens de erro estimados com um intervalo de confiança de $95 \%$.

\section{DISCUSSÃO}

Os territórios pesquisados são áreas de pobreza rural. Os principais ativos que potencialmente permitem a melhoria de vida são a terra e a mão de obra. Se esses ativos podem ser produtivos na atividade agropecuária, o apoio à inserção comercial e às políticas de assistência técnica e crédito podem ajudar os agricultores em seu desenvolvimento. Considerando a produtividade da terra avaliada como ótima, boa ou regular por $80,5 \%$ dos domicílios e o investimento da mão de obra das famílias na produção agropecuária em $80,8 \%$ dos casos, infere-se que os agricultores percebem potencial de desenvolvimento rural a partir dos ativos (terra e mão de obra) empregados na atividade agropecuária.
Não obstante, o acesso a mercados é hoje principalmente facilitado pelos atravessadores com apenas $11,3 \%$ de casos de inserção comercial via cooperativas e associações. As políticas de crédito e assistência técnica são restritas a $20,7 \%$ e 19,8\% dos domicílios respectivamente. Esses gargalos têm restringido o desenvolvimento do grupo de agricultores que potencialmente pode melhorar de vida a partir da inclusão produtiva de seus ativos. Um contexto institucional mais favorável pode reverter o quadro atual em que o trabalho na produção agropecuária resulta em desempenho inferior ao trabalho não agrícola para terceiros.

Existe, portanto, grande margem para o fortalecimento das ações públicas em favor do desenvolvimento rural pela 
inclusão produtiva e aumento da renda do trabalho das famílias (veja ABRAMOVAY, 1992; NERI; MELO; MONTE, 2012; MEDINA; NOVAES, 2014). Nos casos em que as políticas estão sendo efetivamente acessadas pelos agricultores (em cerca de $20 \%$ dos casos), os resultados de desenvolvimento são positivos. A ampliação da ação das políticas pode garantir a inclusão produtiva de mais $60 \%$ do total de domicílios rurais amostrados.

Para os casos em que há pouca disponibilidade de ativos, outras alternativas que, possivelmente, não passam pela produção rural agropecuária, devem ser consideradas. Esse grupoé composto pelos cerca de $20 \%$ dos entrevistados que percebem não possuir os ativos necessários para a produção agropecuária. Nesses casos, em curto prazo, a continuidade das políticas de transferência de renda é crucial (veja GRAZIANO, 2001), salientando-se que, dentre famílias mais pobres da amostra, ainda existem $34,2 \%$ que não estão sendo beneficiadas pelo programa Bolsa Família.

Os resultados mostram que, entre as opções de trabalho fora do domicílio, estão em melhores condições aqueles que exercem trabalho não agrícola para terceiros. Em médio prazo, a educação voltada para o mercado de trabalho urbano pode ser uma alternativa relevante. Não obstante, na amostra, ainda existem 9,7\% das crianças em idade escolar que estão fora de sala de aula. Além do desafio de inclusão numérica, a educação para o público rural hoje passa pelo desafio de garantir a formação aos agricultores e suas famílias que querem seguir na atividade agropecuária e também de habilitar aqueles que querem sair da zona rural para se inserir no mercado de trabalho não agrícola.

Os agricultores familiares, que representam 54,2\% dos domicílios analisados, são um pouco mais pobres do que os não familiares e se enquadram no perfil descrito acima de divisão entre domicílios com potencial de desenvolvimento a partir da produção agropecuária e do- micílios que precisam de alternativas. A situação atual dos agricultores familiares contrasta com a noção de que a agricultura familiar tem hoje grande potencial de ser protagonista do desenvolvimento rural (SACHS, 2001) desses territórios com menor dinamismo econômico. Em vez de um segmento à parte, nesses territórios a agricultura familiar é um produto de seu meio e enfrenta as mesmas dificuldades dos demais domicílios rurais.

Essa avaliação está de acordo com a análise preliminar do Censo Demográfico de 2010 feita por Del Grossi (2012), que indica que a agricultura familiar representa o segundo maior grupo em extrema pobreza no Brasil rural. Os resultados também coincidem com estudos sobre o conjunto de estabelecimentos rurais brasileiros que revelam que $72,95 \%$ têm renda inferior a dois salários mínimos mensais (ALVES; ROCHA, 2010).

O desenvolvimento da agricultura familiar está atrelado ao desenvolvimento desses territórios rurais e vice-versa. Nesses territórios, o desenvolvimento local pode ser promovido pelo maior apoio à inclusão produtiva dos agricultores familiares a partir dos potenciais existentes nas propriedades e no território (VAN DER PLOEG, 2000). Ações nesse sentido são fundamentais para reverter o quadro atual de políticas orientadas para a assistência social, mas com menor enfoque nas ações públicas que buscam alterações mais estruturais em favor das famílias rurais pobres (ZIMMERMANN et al., 2014).

Finalmente, há diferenças regionais importantes no campo brasileiro (KAMIMURA; OLIVEIRA; BURANI, 2010) que são refletidas na percepção dos agricultores. Os agricultores do Norte e Nordeste se percebem em condições de maior pobreza. Não obstante, áreas rurais com depressão socioeconômica são encontradas em todo o país e as características das famílias rurais pobres são similares nas diferentes regiões. O perfil do problema e as soluções possíveis são parecidos, 
sugerindo que a velha pobreza rural (POCHMANN; AMORIN, 2003) segue presente no campo e sua superação passa pela superação de seus fatores causadores históricos (CASTRO, 1965). É fundamental que novas análises sejam feitas no futuro para avaliar em que as ações em curso promovem um processo de democratização que liberta os indivíduos para o desenvolvimento (MARTINS, 1999; SEN, 1999).

\section{CONCLUSÃO}

Enquanto cerca de $80 \%$ dos domicílios em territórios rurais empobrecidos no Brasil têm ativos disponíveis para a produção, apenas cerca de $20 \%$ têm acesso às condições de comercialização e às políticas públicas. A maior capilaridade e articulação das políticas agrícolas poderia garantir a inclusão produtiva de $60 \%$ da população rural que possui ativos potenciais.

Para cerca de $20 \%$ das famílias, as áreas muito pequenas, a baixa produtividade da mão de obra e a péssima capilaridade das políticas restringem o desenvolvimento pela agricultura. Tais condições conduzem à necessidade imediata de medidas assistenciais de transferência de renda e de alternativas de trabalho fora do rural.

\section{REFERÊNCIAS}

ABRAMOVAY, R. Paradigmas do capitalismo agrário em questão. São Paulo: Hucitec, 1992.

ALVES, E.; ROCHA, D. Ganhar tempo é possível? In: GASQUES, J.; VIEIRA, A. (Ed.). A agricultura brasileira. Brasília: MDA, 2010.

BRASIL. Lei federal 11326/2006, de 24 de julho de 2006. Estabelece as diretrizes para a formulação da Política Nacional da Agricultura Familiar e Empreendimentos Familiares Rurais. 2006.

CASTRO, J. Geografia da fome - o dilema brasileiro: pão ou aço. São Paulo: Brasiliense, 1965. 332p.

CENTRO DE ESTUDOS AVANÇADOS EM ECONOMIA APLICADA (CEPEA). Perspectivas para o Agronegócio em 2015. Piracicaba: CEPEA, 2014. 5p.
DELGADO, N.; GRISA, C. Políticas de desenvolvimento territorial e pobreza rural no Brasil. Estudos Sociedade e Agricultura, v. 22, n. 1, p. 132-163, 2014.

DEL GROSSI, M. Extrema pobreza rural do Brasil em 2010. Texto de trabalho preliminar para discussão interna no Ministério do Desenvolvimento Agrário (MDA) e no Governo Federal, voltado ao público da extrema pobreza. MDA, Brasília, 2012 (mimeo)

ECHEVERRI, R. Identidade e território no Brasil. Brasília: IICA, 2009.

FERREIRA, D. Território, territorialidade e seus múltiplos enfoques na ciência geográfica. Campo-Território: revista de geografia agrária, v. 9, n. 17, p. 111-135, 2014.

FRANÇA, C. G.; DEL GROSSI, M. E.; MARQUES, V. A. O censo agropecuário 2006 e a agricultura familiar no Brasil. Brasília: MDA, 2009. 96p.

GRAZIANO DA SILVA, J. Quem precisa de uma estratégia de desenvolvimento. Textos para discussão.Nead, Campinas, SP, v. 2, p. 5-52, 2001.

GUILHOTO, J.; AZZONI, C.; SILVEIRA, F.; ICHIHARA, S.; DINIZ, B.; MOREIRA, G. PIB da agricultura familiar: Brasil-Estados. Brasília: MDA, 2007. 172 p.

HOFFMANN, R.; NEY, M. A recente queda da desigualdade de renda no Brasil: análise de dados da PNAD, do Censo Demográfico e das Contas Nacionais. Econômica, v. 10, n. 1, p. 7-39, 2008.

INSTITUTO BRASILEIRO DE GEOGRAFIA E ESTATÍSTICA (IBGE). Censo Demográfico 2010 (IBGE) - Domicílios particulares permanentes ocupados. Disponível em: <http://www. ibge.gov.br>. Acessado em 21/12/2010.

Brasil em Síntese - Contas Nacionais - PIB per capita 2009/2015. Disponível em: $<$ http://brasilemsintese.ibge.gov.br/contasnacionais/pib-per-capita.html>. Acesso em: 10 out. 2016.

INSTITUTO DE PESQUISA ECONÔMICA APLICADA (IPEA). PNAD 2014 - Breves análises. Brasília: IPEA, 2015. 49p.

KAMIMURA, A.; OLIVEIRA, A.; BURANI, G. A agricultura familiar no Brasil: um retrato do desequilíbrio regional. Interações, v. 11, n. 2, p. 217-223, jul./dez. 2010. 
LEITE, S. P.; WESZ JÚNIOR, V. J. Um estudo sobre o financiamento da política de desenvolvimento territorial no meio rural brasileiro. Revista de Economia e Sociologia Rural, Brasília, v. 50, n. 4, p. 645-666, out./ dez. 2012.

MARTINS, J. S. O poder do atraso. Ensaios de sociologia da história lenta. 2. ed. São Paulo: Hucitec, 1999.

MEDINA, G.; NOVAES, E. Percepção dos agricultores familiares brasileiros sobre suas condições de vida. Interações, Campo Grande, MS, v. 15, n. 2, p. 385-397, jul./dez. 2014.

MINISTÉRIO DO DESENVOLVIMENTO AGRÁRIO (MDA). Territórios da Cidadania. 2008. Disponível em: <http://www.mda. gov.br/sitemda/sites/sitemda/files / ceazinepdf/3638408.pdf $>$. Acesso em: 12 dez. 2013.

NERI, M.; MELO, L.; MONTE, S. Superação da pobreza e a nova classe média no campo. Rio de Janeiro: Editora FGV, 2012. 312p.

NEY, M.; SOUZA, P.; PONCIANO, N. Desigualdade de renda e mudanças recentes na precariedade do emprego na agricultura, indústria e serviços. Estudos Sociedade e Agricultura, v. 19, n. 2, p. 314-343, 2011.
POCHMANN, M.; AMORIM, R. Atlas da exclusão social no Brasil. 2. ed. São Paulo: Cortez, 2003. 221p.

SACHS, I. Brasil rural: da redescoberta à invenção. Estudos Avançados, v. 15, n. 43, p. 75-82, 2001.

SEN, A. Development as freedom. Oxford: Oxford University Press, 1999.

VAN DER PLOEG, J. D.; RENTING, H.; BRUNORI, G.; KNICKEL, K.; MANNINON, J.; MARSDEN, T.; VENTURA, F. Rural development: from practices and policies towards theory. Sociologia ruralis, v. 40, n. 4, p. 391-408, 2000.

VEIGA, J. O Brasil rural precisa de uma estratégia de desenvolvimento. Brasília: MDA/CNDRS/ NEAD, 2001.

WALTER, M. I. Estimação do ICV em 37 territórios rurais. Brasília: IICA/MDA/SDT, 2011. 88p.

ZIMMERMANN, S.; GRISA, K.; TECCHIO, A.; LEITE, S.; BONNAL, P.; CAZELLA, A.; DELGADO, A.; MALUF, R.; MATTEI, L. Desenvolvimento territorial e políticas de enfrentamento da pobreza rural no Brasil. Campo-Território: revista de geografia agrária, v. 9, n. 17, p. 540-573, 2014.

\section{Sobre os autores:}

Gabriel Medina: Professor da Escola de Agronomia da Universidade Federal de Goiás (UFG). Pós-doutor em Políticas Ambientais pelo Imperial College London (Reino Unido). Doutor em Ciências Naturais pela Universidade de Freiburg (Alemanha). Licenciado Pleno em Ciências Agrárias com mestrado em Agriculturas Familiares e Desenvolvimento Sustentável pela Universidade Federal do Pará. Coordenador do Programa de Pósgraduação em Agronegócio da UFG. E-mail: gabriel.silva.medina@gmail.com

Evandro Novaes: Professor da Escola de Agronomia da UFG. Graduação em Engenharia Florestal pela Escola Superior de Agricultura Luiz de Queiroz da USP, mestrado em Genética e Melhoramento pela Universidade Federal de Viçosa e PhD em Forest Resources and Conservation pela University of Florida. E-mail: evandro@ufl.edu

Sônia Milagres Teixeira: Professora na área Desenvolvimento Rural da Escola de Agronomia da UFG. Bacharelado e Licenciatura de Matemática pela Universidade Federal de Viçosa, mestrado em Economia Rural - University of Wisconsin - Milwaukee e doutorado em Economia Rural - Purdue University. E-mail: soniamilagresteixeira@ gmail.com 